\title{
CHARACTERISATION OF PSEUDORABIES VIRUS IN DOMESTIC PIGS AND WILD BOARS IN CROATIA
}

\author{
Tomislav Keros ${ }^{1 *}$, Dragan BrNiĆ1 ${ }^{1}$ Jelena PrPIĆ ${ }^{1}$, Danko DeŽĐEK ${ }^{2}$, Lorena JeMERŠÍ ${ }^{1}$, \\ Besi Roić ${ }^{1}$ and Tomislav BEDEKOvić ${ }^{1}$ \\ ${ }^{1}$ Department of Virology and ${ }^{2}$ Department of Pathology, Croatian Veterinary Institute, \\ Savska cesta 143,10 000 Zagreb, Croatia
}

(Received 13 January 2014; accepted 25 June 2014)

Serological data imply that pseudorabies (Aujeszky's disease) is present in domestic pigs and wild boars in Croatia. Therefore, this study included testing of brain tissue samples collected from 200 domestic pigs and 105 wild boars originating from seventeen districts of Croatia. The presence of pseudorabies virus (PrV) DNA was confirmed in samples originating from six domestic pigs $(3 \%)$ and one wild boar $(0.95 \%)$. Positive samples were sequenced and analysed on the basis of a gC genome fragment. PrV strains have shown to be genetically identical and they are strongly related to some representative strains in the relatively heterogeneous Clade A. The results clearly show that PrV is still circulating among the domestic pig population in Croatia. Furthermore, the presence of pseudorabies virus in wild boars underlines the importance of this species as a PrV reservoir. Continued surveillance is necessary to track the viral spread in order to achieve final eradication of the disease.

Key words: Domestic pig, wild boar, Croatia, pseudorabies, Suid herpesvirus-1, phylogenetic analysis

Pseudorabies (Aujeszky's disease) is a highly contagious viral disease of pigs which causes vast economic losses, particularly on large breeding farms. Domestic animals such as dogs, cats, sheep, goats, cattle and rarely horses or even donkeys can also be infected with the virus. The disease occurs in wild boars as well and may be transmitted to domestic pigs or wild animals, particularly carnivores (Sámi et al., 2007; Müller et al., 2011; Boadella et al., 2012).

The causative agent of the disease is Suid herpesvirus 1 - SuHV1 (Pseudorabies virus $-\operatorname{PrV}$ ), which belongs to the Varicellovirus genus, Herpesviridae family, Suid alphaherpesvirinae subfamily, and is virulent for the majority of mammalian species excluding higher primates and humans. The virus genome is a double-stranded linear DNA molecule, 140-150 kb, which encodes for 72 genes. The viral membrane contains eleven glycoproteins ( $\mathrm{gB}, \mathrm{gC}, \mathrm{gD}, \mathrm{gE}, \mathrm{gG}, \mathrm{gH}, \mathrm{gI}$,

\footnotetext{
"Corresponding author; E-mail: keros@veinst.hr; Phone/Fax: 00385 (1) 612-3675
} 
$\mathrm{gK}, \mathrm{gL}, \mathrm{gM}$ and $\mathrm{gN})$. Glycoproteins $\mathrm{gC}, \mathrm{gD}, \mathrm{gE}$ and $\mathrm{gL}$ have a key role in virus virulence while $\mathrm{gB}$ has a transcriptional activity (Pomeranz et al., 2005).

The molecular characterisation of $\mathrm{PrV}$ is commonly performed by restriction fragment length polymorphism (RFLP) using BamHI, whereas PrV strains can be grouped into four major genotypes. Recently, a highly divergent fragment within the PrV gC has been used for phylogenetic analysis and typing. Data regarding the analysis of $\mathrm{gC}$ reveal a predominance of PrV genotype I in the European wild boar. Furthermore, among the European PrV strains originating from wild boars, two distinct clades, designated as Clade A and Clade B, have been described (Müller et al., 2010; Steinrigl et al., 2012).

PrV infection causes different disorders and mostly affects the central nervous system. The clinical course of the disease depends on the age of animals, the virulence of the virus strain and the hosts' immune status; therefore, if animals survive a PrV infection, it always ends up in a latent stage. Compared to domestic pigs, PRV infection of wild boars often has a more moderate clinical course. Usually, only respiratory signs are present, although e.g. in Germany and Spain more severe disorders of the nervous system have been described (RuizFons et al., 2007; Müller et al., 2010).

Our study describes the detection of PrV DNA in brain tissue samples after carrying out a wide-ranging viral prevalence survey including domestic pigs and wild boars, based on the highly conserved gB genome fragment. For additional confirmation of the infection and for the phylogenetic analysis of Croatian $\mathrm{PrV}$ strains, a variable sequence of the $\mathrm{gC}$ gene was compared with known sequences of $\operatorname{PrV} \mathrm{gC}$ fragments from the GenBank.

\section{Materials and methods}

The study included brain tissue samples collected from 200 domestic pigs originating from seven districts, showing no visible signs of pseudorabies, and 105 hunted wild boars from seventeen districts in Croatia. Samples were taken in 2012 by experts trained in pathology.

For testing, $25 \mathrm{mg}$ pieces of the olfactory bulbs, trigeminal ganglia and brainstem tissue were homogenised by a Microdismembrator device (Sartorius, Goettingen, Germany) and supernatants were prepared for DNA extraction by QIAmp Mini (250) Kit (Qiagen, Hilden, Germany) according to the manufacturer's instructions.

\section{Amplification and sequencing}

DNA amplification was carried out by Platinum Taq Polymerase Kit (Invitrogen, Carlsbad, USA) in a Gene Amp PCR System 9700 Thermocycler (Applied Biosystems, Foster City, USA). For screening purposes, we used two sets of primers in a nested PCR protocol that amplifies a fragment within the highly 
conserved gB gene, according to Ruiz-Fons et al., 2007). At the first stage primers For 5'-ATGGCCATCTCGCGCTGC-3' and Rev 5'-ACTCGCGGTCCTCCA GCA-3' (334-bp products), while at the second stage primers For 5'-ACGGCACGG GCGTGATC-3' and Rev 5'-GGTTCAGGGTACCCCGC-3' (195-bp products) were used for amplification.

To confirm the results, positive samples were re-tested as described by Müller et al. (2010). The target was a genome fragment within the variable $\mathrm{gC}$ gene. The cycling conditions were modified and they included initial denaturation at $94{ }^{\circ} \mathrm{C}$ for $3 \mathrm{~min}, 40$ cycles of $94^{\circ} \mathrm{C}$ for $30 \mathrm{~s}, 61{ }^{\circ} \mathrm{C}$ for $45 \mathrm{~s}$ and $72{ }^{\circ} \mathrm{C}$ for $45 \mathrm{~s}$ with the final extension step at $72{ }^{\circ} \mathrm{C}$ for $7 \mathrm{~min}$. The results were visualised after capillary electrophoresis in $1.5 \%$ agarose gel.

Positive $\mathrm{gC}$ samples were purified with Wizard SV Gel and PCR CleanUp System (Promega, Madison, USA) and submitted to Macrogen (Amsterdam, The Netherlands), using the sequencing Big Dye TM Terminator Kit and ABI 3730XL (Applied Biosystems).

\section{Alignment and phylogenetic analysis}

The first comparison of Croatian PrV sequences with $\operatorname{PrV}$ reference strains ( $\mathrm{gC}$ genome fragment) from the GenBank was performed by the use of the BLAST programme (http://blast.ncbi.nlm.nih.gov/Blast.cgi). Pairwise multiple sequence alignment was performed using the ClustalW (1.6) program implemented in MEGA5 software (Tamura et al., 2011). The formation of phylogenetic trees was accomplished using the same software by implementing the Neighbour-Joining (NJ) method with p-distance (gaps removed) for nucleotide or amino acid sequences (the latter not shown). The clustering stability of the NJ tree was evaluated by bootstrap analysis with 1000 replicates. Nucleotide and amino acid pairwise identity matrix was calculated on previously aligned sequences using BioEdit version 7.1.3.0 (Hall, 1999). The GenBank accession numbers of all reference sequences used for phylogenetic comparisons are indicated in the phylogenetic tree (Fig. 1). The PrV sequences characterised in the present study have been deposited to the GenBank under accession numbers KC865672-KC865678.

\section{Results}

Samples of brain tissue suspensions of six domestic pigs from Zagreb district and of one wild boar hunted in Primorsko-Goranska district were shown to be positive after both PCR protocols performed (for $\mathrm{gB}$ and $\mathrm{gC}$ ).

Analysis of the $\mathrm{PrV}$ gB genome fragment confirmed only the presence of swine herpesvirus 1 (SuHV-1) in the tested samples. Therefore, phylogenetic analysis was conducted on seven out of nine PCR products for the partial $\mathrm{gC}$ genome region that had provided adequate results upon direct sequencing (Table 1). 


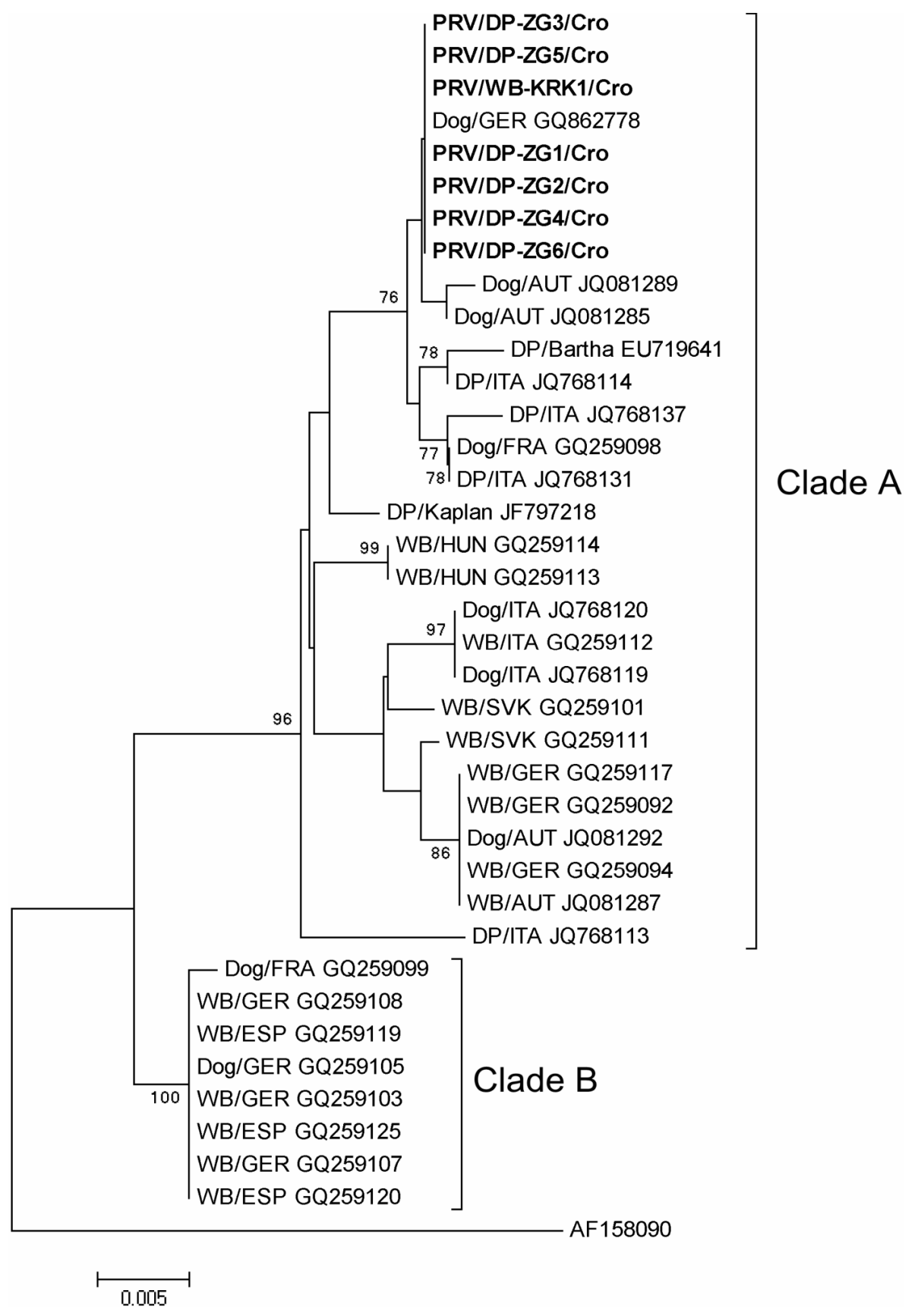

Fig. 1. Phylogenetic relationships of Croatian PrV strains and selected reference PrV strains. The phylogenetic tree is based on the partial gC coding region $(\sim 660 \mathrm{nt})$ of the PrV genome. GenBank accession numbers for selected PrV reference strains are listed within taxa. The Chinese strain was included as an outgroup. The scale bar represents the number of nucleotide substitutions per site 
Table 1

PrV isolates from domestic pigs and wild boars included in the present study

\begin{tabular}{lccccc}
\hline $\begin{array}{l}\text { Sequence } \\
\text { ID }\end{array}$ & $\begin{array}{c}\text { Collection } \\
\text { date (year) }\end{array}$ & $\begin{array}{c}\text { Host } \\
\text { species }\end{array}$ & $\begin{array}{c}\text { Isolation } \\
\text { source }\end{array}$ & $\begin{array}{c}\text { Isolate } \\
\text { ID }\end{array}$ & $\begin{array}{c}\text { GenBank } \\
\text { accession no. }\end{array}$ \\
\hline Seq1 & 2012 & Sus scrofa domesticus & Brain & PRV/DP-ZG1/Cro & KC865672 \\
Seq2 & 2012 & Sus scrofa domesticus & Brain & PRV/DP-ZG2/Cro & KC865673 \\
Seq3 & 2012 & Sus scrofa domesticus & Brain & PRV/DP-ZG3/Cro & KC865674 \\
Seq4 & 2012 & Sus scrofa domesticus & Brain & PRV/DP-ZG4/Cro & KC865675 \\
Seq5 & 2012 & Sus scrofa domesticus & Brain & PRV/DP-ZG5/Cro & KC865676 \\
Seq6 & 2012 & Sus scrofa domesticus & Brain & PRV/DP-ZG6/Cro & KC865677 \\
Seq7 & 2012 & Sus scrofa wild boar & Brain & PRV/WB-KRK1/Cro & KC865678 \\
\hline
\end{tabular}

All seven Croatian PrV strains derived from domestic pigs and wild boar proved to be $100 \%$ identical in partial $\mathrm{gC}$ nucleotide (nt) and amino acid (aa) sequences. They provisionally cluster within the relatively heterogeneous Clade A which comprises the majority of already characterised PrV strains (Fig. 1). The closest nt/aa identity was found for the PRV strain detected in a hunting dog from Germany - GQ862778 (Müller et al., 2010), having 100\% identity on nt/aa level. Pseudorabies virus strains characterised in Austria (Steinrigl et al., 2012) that were marked as Lineage 2 representatives in the same Clade A, clustered along with our strains as well (Fig. 1).

\section{Discussion}

Domestic pigs and wild boars are natural hosts of PrV, which has recently been emerging worldwide. Simultaneously, over the last few decades an increase of the wild boar population, acting as possible PrV transmitters, has been recorded in most European countries. Serological surveys and virological screenings have shown that in many regions of Europe the prevalence of $\mathrm{PrV}$ in populations of wild boar is higher than expected (Vicente et al., 2005; Müller et al., 2011; Wodak, 2011; Boadella et al., 2012).

Therefore, in many European countries, attempts are made to reduce $\operatorname{PrV}$ infection in wild boars, and in Croatia the success of such attempts is monitored by serological tests, mostly by ELISA (Roić et al., 2012). A correct diagnosis can be obtained by PrV isolation or by molecular detection of the viral DNA, but ELISA tests are highly sensitive and specific, and the PrV seroprevalence thus determined gives us valuable information on the circulating virus strains and may help to identify epidemiological links (Belák, 2005; Fonseca et al., 2012).

Recently, Müller et al. (2010) have reported an increasing number of $\operatorname{PrV}$ infections in border regions between Germany and Belgium, Germany and Po- 
land as well as Hungary and Serbia. Since Croatia borders with Hungary, Slovenia and Serbia, the possibility of PrV spread, especially among wild boars, is increased (Vengust et al., 2005; Müller et al., 2011; Pušić et al., 2011; Wodak, 2011).

In Croatia, the population density of wild boar has been increasing for more than a decade. In 2010, according to official statistics, the annual hunting bag amounted to 12,468 animals, resulting in an estimated population density of approximately 53,000 individuals. In Croatia, serosurveys among wild boar revealed seroprevalences ranging from $28.1 \%$ to $55 \%$ in 2012 and 2002, respectively (Župančić et al., 2002; Roić et al., 2012).

In our research, based on samples of brain tissue suspension taken by screening domestic pigs and from hunted wild boar, $\operatorname{PrV}$ was confirmed in two of several districts. The study confirmed that in Croatia the same type of $\operatorname{PrV}$ is circulating in populations of domestic pigs and wild boars, which points to the increased need of implementing adequate control measures including both populations. Our results show that PrV strains detected in domestic pigs as well as wild boars in Croatia belong to Clade A, although the presence of other genotypes cannot be excluded.

The PrV sequences of isolates from wild boar were similar to, or identical with, sequences from domestic pigs, which, according to Hahn et al. (2010) suggest recent transmission from roaming domestic pigs. In the Mediterranean countries and in the Balkans, outdoor pig farms with free-roaming pigs used for ham production pose an additional risk. Consequently, it is important to implement adequate biosecurity measures and prevent contact between domestic pigs and wild boars (Wyckoff et al., 2009).

PrV transmission from wild boars to domestic pigs cannot be entirely prevented. Therefore, efficient biosecurity measures should be implemented, especially if the farmer is also a hunter. Along with the prevention measures and periodical serological monitoring biannually or triennially, the monitoring should be particularly increased during the hunting seasons. In addition to that, maintaining the pseudorabies-free status of regions is necessary and a precise and efficient molecular detection of $\mathrm{PrV}$ in tissues of wild animals is of great importance. Isolation and molecular categorisation of PrV from infected wild boars can facilitate the detection of the chain of infection and also help in assessing the population variety.

The large share of latently infected wild boars in the spreading of $\operatorname{PrV}$ has encouraged us to describe in detail the characteristics of the disease and the molecular detection of the virus and in particular, to alert pig owners and hunters to the possibility of $\mathrm{PrV}$ transmission from wild boars to domestic animals. This study also stresses the value of the molecular detection of PrV. Further research and categorisation of isolates from a larger number of samples are needed in order to focus on the transmission of PrV from wild boars and to develop measures for eradication of the disease. 


\section{Acknowledgement}

The authors would like to thank Professor Thomas Müller (Institute of Molecular Virology and Cell Biology, Friedrich-Loeffler-Institute, Federal Research Institute for Animal Health, Greifswald - Insel Riems, Germany) for support and help in the choice of literature.

\section{References}

Belák, S. (2005): The molecular diagnosis of porcine viral diseases: a review. Acta Vet. Hung. 53, $113-124$.

Boadella, M., Gortazar, C., Vicente, J. and Ruiz-Fons, F. (2012): Wild boar: an increasing concern for Aujeszky's disease control in pigs. BMC Vet. Res. 8, 7 http://www.biomedcentral.com/ 1746-6148/8/7.

Fonseca, Jr. A. A., Camargos, M. F., Sales, M. L., Heinemann, M. B., Leite, P. C. and Reis, J. K. P. (2012): Pseudorabies virus can be classified into five genotypes using partial sequences of UL44. Braz. J. Microbiol. 43, 1632-1640.

Hahn, E. C., Fadl-Alla, B. and Lichtensteiger, C. A. (2010): Variation of Aujeszky's disease viruses in wild swine in USA. Vet. Microbiol. 143, 45-51.

Hall, T. A. (1999): BioEdit: a user-friendly biological sequence alignment editor and analysis program for Windows 95/98/NT. Nucl. Acids Symp. Ser. 41, 95-98.

Müller, T., Hahn, E. C., Tottewitz, F., Kramer, H., Klupp, B. G., Mettenleiter, T. C. and Freuling, C. (2011): Pseudorabies virus in wild swine: a global perspective. Arch. Virol. 156, 1691-1705.

Müller, T., Klupp, B. B., Freuling, C., Hoffman, B., Mojcicz, M., Capua, J., Palfi, V., Toma, B., Lutz, W., Ruiz-Fons, F., Gortazar, C. and Mettenleiter, T. C. (2010): Characterisation of pseudorabies virus of wild boar origin from Europe. Epidemiol. Infect. 138, 1590-1600.

Pomeranz, L. E., Reynolds, A. E. and Hengartner, C. J. (2005): Molecular biology of pseudorabies virus: Impact on neurovirology and veterinary medicine. Microbiol. Mol. Biol. Rev. 69, 462-500.

Pušić, J., Prodanov, J., Došen, R., Stojanov, I., Stojanović, D. and Petrović, T. (2011): Epizootical characteristics of Aujeszky's disease in Vojvodina region and biosecurity concerns. Biotechnol. Anim. Husb. 27, 875-882.

Roić, B., Jemeršić, L., Krovina, Z., Tepšić, S., Jungić, A., Keros, T., Prpić, J. and Brnić, D. (2012): National surveillance programme of Aujeszky's disease in domestic pigs in the Republic of Croatia during 2011. Vet. Stanica 43, 19-26.

Roić, B., Jemeršić, L., Terzić, S., Keros, T., Balatinec, J. and Florijančić, T. (2012): Prevalence of antibodies to selected viral pathogens in wild boars (Sus scrofa) in Croatia in 2005-2006 and 2009-2010. J. Wildl. Dis. 48, 131-137.

Ruiz-Fons, F., Vidal, D., Hofle, U., Vicente, J. and Gortazar, C. (2007): Aujeszky's disease infection patterns in European wild boar. Vet. Microbiol. 120, 241-250.

Sámi, L., Ursu, K., McKillen, J., Kecskeméti, S., Belák, S. and Kiss, I. (2007): Simultaneous detection of three porcine viruses by multiplex PCR. Acta Vet. Hung. 55, 267-276.

Steinrigl, A., Revilla-Fernandez, S., Kolodziejek, J., Wodak, E., Buyo, Z., Nowotny, N., Schmoll, F. and Köfer, J. (2012): Detection and molecular characterization of Suid herpesvirus type 1 in Austrian wild boar and hunting dogs. Vet. Microbiol. 157, 276-284.

Tamura, K., Peterson, D., Peterson, N., Stacher, G., Nei, M. and Kumar, S. (2011): MEGA5: Molecular Evolutionary Genetics Analysis using Maximum Likelihood. Evolutionary Distance and Maximum Parsimony Methods 28, 2731-2739.

Vengust, G., Valencak, Z. and Bidovec, A. (2005): Presence of antibodies against Aujeszky's disease virus in wild boar (Sus scrofa) in Slovenia. J. Wildl. Dis. 45, 800-802. 
Vicente, J., Ruiz-Fons, F., Vidal, D., Höfle, U., Acevedo, P., Villanúa, D. V., Fernández-de-Mera, J. G., Martín, M. and Gortázar, P. C. (2005): Serosurvey of Aujeszky's disease virus infection in European wild boar in Spain. Vet. Res. 35, 243-253.

Wodak, E. (2011): Die Aujeszkysche Krankheit beim Wildschwein - Diagnostik und bisherige Ergebnisse. Wildschwein in Österreich. AGES 02.02.2011; http://www.ages.atagesueberuns/ages-akademie/documentation-2011.

Wyckoff, A. C., Henke, S. E., Campbell, T. A., Hewitt, D. G. and Vercauteren, K. C. (2009): Feral swine contact with domestic swine: a serologic survey and assessment of potential transmission. J. Wildl. Dis. 45, 422-429.

Župančić, Z., Jukić, B., Lojkić, M., Čač, Z., Jemeršić, L. and Starešina, V. (2002): Prevalence of antibodies to classical swine fever, Aujeszky's disease, porcine reproductive and respiratory syndrome, and bovine viral diarrhea viruses in wild boars in Croatia. J. Vet. Med. B 49, 253-256. 